\title{
The Case for a Market for Transplantable Organs
}

\author{
Gilbert Berdine MD
}

A market exists wherever two people engage in voluntary exchange. A market, by definition, precludes coercion for the exchange. Markets exist because of the subjective nature of value. Two people assign a different valuation to the same thing making possible an exchange where both parties perceive an increase in value from the exchange. Markets are not zero sum games.

Not all organs are equally suitable for a market based exchange. We each only have one heart and one liver and cannot survive without them; these organs are not well suited for market exchange. Bone marrow is a replenishable resource; it is well suited for repeated exchange. Some organs, such as the kidney, exist in pairs, and we can do very well with only one. While there is unquestionable value of the second kidney to its owner, the owner may place a lower value on the second kidney than another person who had no kidneys. The donor is willing to part with one kidney, not because it has no value, but because the recipient is willing to pay a sufficient price that the donor will put to use in satisfying other wants and needs that would go unmet absent the exchange.

The kidney is the easiest focal point for this discussion as it is the largest potential market given the current transplant technology. According to the Scientific Registry of Transplant Recipients, the number of people waiting for kidney transplant increased from 83,879 at the start of 2011 to 86,547 at the end of $2011 .{ }^{1}$ There were 28,131 new patients added to the list and 25,463 removed from the list. Of those removed, 10,399 received deceased donor kidneys, 4,922 received live donor kidneys, 5,139 died while

Corresponding author: Gilbert Berdine MD Contact Information: Gilbert.Berdine@ttuhsc.edu DOI: 10.12746/swrccc 2014.0206.069 waiting for transplant, and 1,903 became too ill for transplant while waiting. ${ }^{1}$ Despite appeals to altruism and programs to recruit deceased donor kidneys, the list has grown from 74,572 at the start of 2009 to 83,879 at the start of $2011 .{ }^{1}$

The donation of organs for commercial gain is illegal in the United States and much of the world. Given the present legal situation, the position opposed to a market for transplantable organs must be considered the mainstream position. A consensus statement on this topic appeared in JAMA in 2000:

"Living organ donors should not personally bear any costs associated with donation. In addition, guidelines should be established that are similar to those for short-term disability to defray lost wages. Nevertheless, direct financial compensation for an organ from a living donor remains controversial and illegal in the United States. The current position of The Transplantation Society, the international organization, should be noted: 'Organs and tissues should be freely given without commercial consideration or commercial profit.' "2

The objections are moral and ethical rather than practical. As expressed by a leading opponent against organ sales, Dr. Delmonico states: "selling one's kidney, selling a part of one's liver, or selling any other part of one's body violates the dignity of the human person." . ${ }^{3} \mathrm{Dr}$. Delmonico takes care to clarify that there is no objection to compensating donors for the costs of procedures or time lost from work due to the donation, but that commercial gain is the source of the ethical violation.

One gets the impression that the objection is not to the process of donation, but rather the objection is to money itself. This impression is reinforced by the existence and support for barter exchanges where a kidney is donated in exchange for an arranged dona- 
tion of another kidney. So, it is neither the process of donation that violates human dignity or trade that violates human dignity, but it is money changing hands that violates human dignity. This appears to be a complete misunderstanding about money. Money is a medium of exchange that avoids a double coincidence of wants that necessarily must exist for barter. A baker who wants shoes must find a cobbler who wants a cake. Money eliminates this problem and greatly expands the opportunities for mutually beneficial exchanges. A potential kidney donor may want medical care for his child, or a better education, or capital to start a business, or any number of other desires; selling a kidney becomes a means to achieve these otherwise unachievable ends. Granted there are some people who would gladly donate a kidney to benefit a loved one, but who would not sell the kidney to a stranger for any price. Why should these people interfere with other people who have different priorities?

Dr. Delmonico's biases against commerce become apparent: "There is indeed an international concern that the poor of several countries are selling kidneys to affluent individuals who have the resources to make that purchase. These sales are inherently coercive." [emphasis mine] ${ }^{3}$ Delmonico's claim that sales are inherently coercive is an assertion without anything to back it up. Delmonico then asks, "What evidence do the authors have that enables the conclusion that the "sale of purchased donor kidneys [that] now accounts for thousands of black market transplants" is "voluntary"?" ${ }^{3}$ Without presenting any evidence for coercion, Dr. Delmonico insists on proof that market based exchanges -- which are by definition voluntary -- are voluntary. Pointing a loaded gun at someone is coercion. Giving someone additional options and asking them to make choices based upon personal valuations is the opposite of coercion.

Another concern is the involvement of criminal elements in both black markets for organs and transplant tourism. Dr. Delmonico states: "The World Health Organization has recently conducted regional meetings in Manila and Karachi to obtain the insights of health officials about the transplant tourism that is occurring. Regional officials agree that the black markets must be eliminated by a concerted effort of the United Nations, just as the black markets for the sale of women and children must be addressed." 3 The sale of women and children, which is clearly a form of slavery and coercive, has nothing to do with voluntary exchanges of organs. Markets are black because they are illegal. While everything coercive should be illegal, not everything illegal is coercive. In the case of organs, black markets have spontaneously appeared to serve a function not permitted by local authorities. The only reason for involvement by criminal elements is that the markets are illegal which makes profit potential sufficiently high to attract the interest of criminals. Similar events plagued the misguided attempt at Prohibition in the U.S., just as it is currently plaguing the misguided War on Drugs.

The opponents of a market for organs wish organ donations to be based on altruism. The evidence clearly indicates that altruism will not clear the market. There are an insufficient number of Mother Theresa figures among us. The common person wants more than satisfaction and compensation for direct costs to donate. Some people waiting for transplant have the means to offer these common donors what they demand. These exchanges will go on. Keeping them illegal will only keep the price higher than it should be, attract criminal elements to the process, and decrease the number of transplants below what society is capable of performing.

Author Affiliation: Dr. Berdine is a pulmonary physician in the Department of Internal Medicine, TTUHSC.

Received: $3 / 4 / 2014$

Accepted: $3 / 28 / 2014$

Reviewers: Melvin Laski MD

Published electronically: 4/15/2014

\section{References}

1. http://srtr.transplant.hrsa.gov/annual_reports/2011/

2. http://jama.jamanetwork.com/article-aspx?articleid $=193360$

3. Kidney International (2006) 69, 954-955. 